no bad effects, I instructed her to take the antipyrin in larger doses and oftener. This she did with complete success. She took 150 gr. as follows:-20 gr. on June 26th at 9 P. M.; June 27 th, 20 gr. at 9 and 1 , and 10 gr. at 6 and 11 ; June 28 th, 10 gr. at 8,12 , 4, and 11 ; 29 th, 10 gr. at 10 and $10 ; 30$ th, 10 gr. at 10 P.M. only. During the period she was not laid up; she had no pain or sickness; she went about housework as usual ; was able to go out of doors; had afterwards no lameness and no desquamation. For the period, July $23 \mathrm{rd}$ to $26 \mathrm{th}$, she used $150 \mathrm{gr}$. with the same result; and $100 \mathrm{gr}$. at the August menstruation acted so satisfactorily that she described it as the best time of all. Iluring the September flow she was able to assist her sister in a busy fancy stationery retail business. Menstruation passed off so well on Oct. 22nd to 24 th that 80 grs. sufficed to prevent the symptoms.

Her general health has much improved, and this fact, with the smaller amount of antipyrin now required, encourages the hope that the improvement may be permanent.

Wimpole-street, $W$.

\section{ALUM ENEMATA IN DYSENTERY.}

By Henry F. Norbury, C.B., M.D., DEPUTY INSPECTOR-GENERAL, ROYAL NAVY.

(Communicated by the Medical Director-General of the Navy.)

Having read in The LANCET of Aug. 31st a paper by Mr. Hepburn on the successful treatment of an obstinate case of dysentery by strong enemata of alum, I was induced to try it in the following case, and with such success that $I$ think it advisable to report it, in order that attention may be drawn to Mr. Hepburn's method. A seaman, aged thirty-one, had contracted dysentery abroad three years and a half previously, and since that time had never enjoyed his usual health. He had frequently suffered from tomina, had from three to ten loose offensive stools daily, accompanied by much tenesmus and by occasional passages of blood, and he bad gradually become feeble and emaciated. During this long period he had frequently been under treatment, but with only slight benefit. He was unable to continue his duties on board ship, and had to return to England, when he came under my observation. His appetite was bad, his tongue foul; he passed, amid much straining, from three to eight loose, frothy, offensive motions daily, sometimes containing blood; but, although griping pains were often very distressing, there was neither tympanites nor abdominal tenderness. e was carefully dieted, and amons the druos prescribed for a long period were compound ipecacuanha powder, aromatic sulphuric acid, decoction of hamatoxylon, lead pill with opium, compound kino powder, chlorodyne, sulphate of copper pill with opium, and liquor ferri pernitratis, besides enemata of opium, of nitrate of silver, and of sulphate of zinc, and suppositories of tannin. I can fairly say that he derived no benefit whatever from any of the above. Lastly, I prescribed an enema containing half an onnce of alum in ten ounces of water, to be administered night and morning. It produced slight sweating at first, but the effect in a couple of days was remarkable; the stools were reduced to one or two daily, and shortly became of natural consistence. This treatment was continued for eighteen days, when the patient expressed himself as feeling better than he had done for years; he had also gained considerably in weight and looked robust. He was kept under observation for some days after the enemata were stopped, to ascertain if there would be any return of his complaint, but as there was none he resumed his ordinary avocations.

Plymouth.

THE FFFECTS OF THE ELECTRIC CURRENT WHEN APPLIED TO THE FEMALE PELVIC ORGANS: A FEW EXPERIMENTS. ${ }^{1}$

BY W. K. M'MoRDIE, M.D.,

SURGEOX, SAMARITAN HOSPITAL FOR WOMEN, BELFAST.

IT is now only a few years since the application of electricity as a therapeutic agent had almost entirely fallen into the hands of quacks. Apostoli has by his energetic efforts prominently brought electric therapeutics before the pro-

I A paper read at a meeting of the Obstetric Section of the Royal Academy of Medicine in Ireland on Nov. 2-2nd. fession and the public, as applied to the treatment of uterine fibroids. The facts adduced and proved by him and others who have been engaged in these experiments are very few. This being so, any ascertained effect of the electric current passing through any organ either in physical change or physiological action is worthy of being recurded and placed before the profession. A few years ago I got a one-celled electric battery, and for some months made a series of observations on the effects produced in uterine hamorrhage when the cause was obscure, and in fibroid tumours. I applied it as follows: One pole attached to a concluctur in the form of a uterine sound placed in the uterus, and the other to a flat conducting surface placed over the abdominal parietes, corresponding to the fundus uteri. Two effects were produced when the current was passed from ten to twenty minutes. In cases where the external os was small it became dilated, and in a large proportion of the cases where the females were healthy the sexual orgasm was produced. It had no effect on the fibroids even after frequent applications. It made no difference whether the positive pole or the negative pole was inserted. The current was constant, and I had no means of measuring it except by the sensations of the patient. It may be said that my battery was too simple and my mode of application not on scientific principles. Nevertheless, I have seen enough to convince me that an electric current passed through the pelvic organs of a female in a fairly healthy condition will in a large proportion of cases produce what I have stated It has been said that the electric treatment sometimes causes intra-uterine fibroids to extrude from the external os; but this frequently takes place without the aid of electricity. Soft fibroids frequently get smaller without any treatment. Hygienic and dietary treatment frequently relieves symptoms connected with fibroids. But mistaken diagnosis will in some cases, at least, account for the disappearance of a supposed fibroid. The following might have been such a case : A lady canie under my care as a private patient in the Samaritan Hospital during the past summer suffering from an abdominal enlargement, which was circumscribed and flattened, about the size of an adult head. She first noticed it about two years previously, and she then placed herself under the care of her family physician; it, however, continued to grow, and at the time she came under my care it certainly might have been reasonably mistaken for a fibroid. During the two years previously to her coming under my care she had consulted two of the leading physicians of the city, and both considered it an organic tumour. When I first saw her she said she would not have an operation performed, but would submit to any other form of treatment. A full enema with an eight-inch pipe proved the tumour to be an accunulation of hardened fæees. What effect electric puncture would have had on this mass it is impossible to say; but certainly had it disappeared under such treatment it would have been counted as a fibroid cured by electricity.

Belfast.

\section{RELAPSING ERYTHEMA OF FACE.} By Tom Robinson, M.D., F.R C.P.

M. H_- aged forty-seven, said she had been subject to erysipelas of the face for many years; that her mother also suffered. The attacks have come on at all times of the year, but she thinks more in the winter than during the summer. She feels quite sure that a sharp current of cold air blowing upon her face would light up the inflam. mation, and on two occasions it has been caused by riding in a train with her face to the engine and the window open. She believes she first had an attack when she was twenty. three years old. I saw her on Feb. 3rô, 1889. The weather was very cold. Two days before she had been out for a walk, and she felt the cold strike her face as if something sharp had been thrown at her. During the evening the bridge of the nose and cheeks felt hot, and she was convinced an attack was coming on. On the second day she remained indoors, and the swelling increased. When I saw her she looked at the first glance exactly like a patient with facial erysipelas. The eyes were nearly closed, the outline of the nose was lost, and there were several resications. I could not discover any wound of the skin, and, what was to my mind of great importance, the contiguous lymphatic glands were not involved. The temperature as taken in the mouth was only $99^{\circ}$. The redness shaded off gradually with the 